\title{
Representação, metafísica da substância e poder em Judith Butler
}

ISSN: $2358-0844$
n. II. v. I mai. -0ut. 2019
p. 127-I38.

ISSN: $2358-0844$
n. II. v. 1 mai. -0ut. 2019
p. $127-138$.

ISSN: $2358-0844$
n. 11 . v. I mai. -0ut. 2019
p. $127-138$.

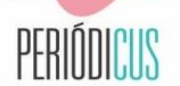

\author{
Pedro Farias Mentor ${ }^{1}$
}

RESUMO: O presente trabalho pretende apresentar minimamente o conceito-prática de representação política tentando demonstra a relação intrínseca com as categorias de sujeito, política, ontologia, cultura e sexualidade partindo do pensamento de Judith Butler em três textos: Sujeito do sexo/gênero/desejo, Tortura e a ética da fotografia: pensando com Sontag e a Introdução do livro $A$ vida psíquica do poder.

PALAVRAS-CHAVE: filosofia contemporânea; Judith Butler; ontologia; representação política; sexualidade.

\begin{abstract}
The present work intends to present the concept-practice of political representation minimally, trying to demonstrate the intrinsic relation with the categories of subject, politics, ontology, culture and sexuality starting from the thought of Judith Butler in three texts: Subject of sex / gender / desire, Torture and the ethics of photography: thinking with Sontag and the Introduction of the book The psychic life of power.

Keywords: contemporary philosophy; Judith Butler; ontology; political representation; sexuality.

Resumen: El presente trabajo pretende presentar mínimamente el concepto-práctica de representación política intentando demostrar la relación intrínseca con las categorías de sujeto, política, ontología, cultura y sexualidad partiendo del pensamiento de Judith Butler en tres textos: Sujeto del sexo / género / deseo, Tortura y la ética de la fotografia: pensando con Sontag y la Introducción del libro La vida psíquica del poder.

Palabras clave: filosofía contemporânea; Judith Butler; ontologia; representación política; sexualidad.
\end{abstract}

${ }^{1}$ Graduando em Filosofia pela Universidade de Brasília (UnB). E-mail: pedrofariasmentor@gmail.com 


\section{Da representação política}

A ideia de representação política responde à relação de um sujeito que será submetido à ação de ser representado, os mecanismos necessários para que haja efetivação e o resultado da operação. Como se fossem componentes do Diagrama de Venn, o sujeito e o aparato de recognição podem e são concebidos talvez mais pela facilidade de imagética de assim os pensarmos do que questionarmos, como mundos que antecedem um ao outro e posteriormente se interseccionam - isso quando, como acontece em inúmeras teses, o primeiro não é a função a priori, o núcleo, que se exterioriza no mundo demonstrando a justa medida do construto jurídico-ético-social.

De um lado, um sujeito que, embora revisado, ampliado, negado, amputado e manipulado de substratos por quase toda tradição ocidental permanece como cadáver a ser trabalhado incessantemente no interior de uma mentalidade alicerçada na universalidade, na antecedência essencial, nos direitos e deveres inegáveis, na dignidade natural, etc. Do outro lado, uma máquina jurídica - e aqui me refiro muito mais a decretos, constituições, medidas provisórias, emendas, declarações, liminares, petições etc. - aliada aos estudos das mais diversas propriedades e formas de escrita - que consagram de forma mais ou menos explícitas, tendo em vista a sua própria natureza, o revelar da verdade dos seus objetos - e que, por serem contingentes em (alguns de) seus métodos devem estar submetidas a atemporalidade das substâncias que lhes dão ensejos respondendo a demanda e a conquista de um absoluto dado. No nosso caso, as matérias mais “corruptíveis” por está ligada ao tempo, ao corpo, a fortuna - que são as práticas políticas.

Essa concepção é de tamanho lastro histórico que soa como uma atitude aberrante, pecaminosa ou até mesmo inumana negar tais tributos bem como a potencialidade da razão de deles admitir enquanto necessários.

Atravessando mais de 1000 de herança política clássica o tema da representação hoje se faz impreterível diante a discussão a respeito de retribuição, do reconhecimento e da revisão crítica da compleição clássica partindo dos paradigmas que a contemporaneidade apresenta ${ }^{2}$ ou das (aparentes)

2 Entre os temas que podemos apontar como paradigmas para o pensamento político moderno: os refugiados, a população LGBT+, os estudos de gênero, o movimento negro, os Crips, as novas instituições sociais e a permanência ou falência das velhas, a economia política, além, é claro, da aproximação, ainda mais intensamente nos meios acadêmicos, de outras áreas do conhecimento normalmente (estrategicamente?) deixas apartadas como a literatura, as artes plásticas, o teatro e o cinema.

Periódicus, Salvador, n.11, v. 1, mai-out.2019 - Revista de estudos indisciplinares em gêneros e sexualidades Publicação periódica vinculada ao Núcleo de Pesquisa NuCuS, da Universidade Federal da Bahia - UFBA ISSN: 2358-0844 - Endereço: http://www.portalseer.ufba.br/index.php/revistaperiodicus 
inesgotáveis fontes do pensamento político antigo, estimulando os estudiosos a revisitar as concepções anteriores e responderem criativa e criticamente aos acontecimentos.

Parte das discussões acerca de democracia contemporânea desde o final do século XX, especialmente a partir da década de 1980, e no início do XXI é a relevância, as modalidades e instrumentos de reconhecimento dos sujeitos em relação às democracias estatais ou de outros que despontam em países destoantes - por exemplo: Coreia do Norte, Somália, Crimeia, Arábia Saudita. Entre os nomes de maiores relevância na área ainda em ativa podemos citar, a título de curiosidade: Iris Marion Young, Anne Phillips e Nancy Fraser.

O jusnaturalismo, que demanda todas as categorias da nossa discussão e na atualidade é assunto hodierno quando o assunto é direitos humanos: um sujeito muito bem definido, um meio no qual a representação será chamada para aplicar uma ordem e uma justificativa anterior ao ato. Segundo Bobbio e demais autores (1998, p.655-656), o jusnaturalismo é a doutrina que admite a existência de direitos naturais anteriores ao direitos positivos no qual esses gozam de validade em si, superioridade e prevalência a estes.

O jusnaturalismo, como teoria jurídica, transformou-se na teoria dos direitos humanos. Estes constituem hoje uma nomenclatura nova para os antigos 'direitos do homem' ou 'direitos naturais', declarados em documentos solenes a partir do século XVIII. A ideia jusnaturalista, assim, não se modificou substancialmente, apenas recebeu uma nova roupagem. (LACERDA, 2011, p.1)

A concepção de Direito Natural de São Tomás de Aquino (1225-1274) se destaca entre muitas outras das correntes jusnaturalistas por conta da sua concepção antropológica do ser humano nevralgicamente entrelaçada às leis eternas e direitos naturais: o homem é feito à imagem e semelhança de Deus - todas as coisas se encerram neles. O fim último - e aqui frisamos: há uma finalidade tracejada - do ser humano e das associações humanas é a felicidade, felicidade esta que é Deus. E para que cheguemos ao estado há de se considerar e ordenar o ato de fazer o bem comum que só será possível em sociedade. Logo "o direito natural vincula inseparavelmente a si o homem individualmente e a sociedade dos homens" (MOURA, 2014, p.36) bem como a lei humana deve estar de acordo sempre com essa ideia. Tomás reconhece três formas de governo legítimos, ou seja, três formas de representações políticas legítimas: monarquia, aristocracia e república, preferenciando a monarquia por três motivos: (I) Teológico: se aproxima do governo de Deus do mundo; (II) Filosófico: Sendo que em tudo há uma unidade e tudo regressa à unidade (natureza), a monarquia se aproxima da natureza; (III) 
Histórico: o passado revela que há discórdia e deriva nos países sem rei. E aqui temos algo que, de maneira até certo ponto secularizada ainda não se erodiu.

Notemos então, pelo menos em um caso - o do Doutor Angélico ${ }^{3}$ - que a categoria de sujeito e representação são relativas aos estudos que jamais se referem, todavia, exclusivamente a táticas imediatas ou planejaveis minuciosamente: ignorada por certos estudiosos centrados muito mais numa práxis política e social que se faz sem considerar antecedentes, há a necessidade de sublinhar a índole metafísica presente desde o ínicio no jogo sujeito-a-ser-representado/representação-DO - e não doS ou alguns, sempre em totalidade evidente e/ou evidenciável, atômica, distinta por ser sem marcação sujeito que tenta escapar, talvez mais nas meditações tradicionais, de tudo o que é acidental assim como a secularização das práticas religiosas. ${ }^{4}$

Ciente da tradição, Judith Butler, embora não dialogue diretamente com Aquino, mas outros grandes nomes - Aristóteles, Beauvoir, Derrida, Foucault, Hegel - opera em suas pesquisas uma analítica do que chama de "metafísica da substância" contribuindo significamente para uma reviravolta na teoria da representação.

\section{Da metafísica da substância: coerência interna}

No primeiro capítulo do seu livro Problemas de Gênero: feminismo e subversão da identidade (1990), "Sujeitos do sexo/gênero/desejo", Butler engendra um longo comentário crítico a respeito da essencialização do sujeito nos sistemas políticos calcados em representações, com um recorte nos movimentos e estudos feministas.

Segundo a autora, com a passagem do tempo, o feminismo engendrou por necessidades sociais o consenso de inteligentiblidade uma "mulher ideal" ao mesmo tempo propiciada e requerida nas articulações internas de sua discursividades. A representação almejada seria uma faca de dois gumes: se em uma ponta ela é a extensão de visibilidade às mulheres enquanto sujeitos político, - e aqui podemos implicar, fora de Butler, a outras categorias ${ }^{5}$ - também seria uma normatização linguística que

3 Mas não exclusivamente: Maquiavel, Hobbes, Locke, Tocqueville e outros debatem a representação, o representante e o representado nas formas de governo e esses nomes são apenas uma pequena porção dos nomes possíveis de serem elencados.

4 O caso de Giorgio Agamben, Walter Benjamin, Carl Schmitt são exemplares nesses tipos de estudo.

5 Indígenas, afrodescendentes, pessoas TBLG+, homens cisgêneros e assim por diante.

Periódicus, Salvador, n.11, v. 1, mai-out.2019 - Revista de estudos indisciplinares em gêneros e sexualidades Publicação periódica vinculada ao Núcleo de Pesquisa NuCuS, da Universidade Federal da Bahia - UFBA ISSN: 2358-0844 - Endereço: http://www.portalseer.ufba.br/index.php/revistaperiodicus 
concomitantemente revelaria e distorceria toda a categoria de um ser e/ou devir mulher:

Os domínios da representação política e linguística estabeleceram a priori o critério segundo o qual os próprios sujeitos são formados, com o resultado de a representação só se estender ao que pode ser reconhecido como sujeito. Em outras palavras, as qualificações do ser sujeito tem que ser atendidas para que que a representação possa ser expandida. (BUTLER, 2012, p.18)

Pensar termos como "gênero", "linguagem", "sexualidade", “ontologia/metafísica" e “identidade" é olvidar as inúmeras e muitas vezes invisíveis imbricações imanentes de uma categoria de análise para outra. Ora, se há uma relação, seja qual for, entre um sujeito que está no tempo e uma realidade ontológica virtual haveria relações entre a(s) substância(s) res cogitans que se diriam fixas e os gêneros dos corpos. As características da identidade, em um primeiro momento, deveriam ser (I) a volta a si mesma, (II) pertencialidade ao longo tempo e (III) coerência interna.

A "pessoa" é toda aquela que teria a capacidade de consciência, linguagem e deliberação moral. Mas para Butler seria um erro supor que a identidade é anterior ao debate de gênero, muito pelo contrário: as pessoas só são reconhecidas como indivíduos por marcadores dessa natureza que estão "em conformidade com padrões reconhecíveis de inteligibilidade do gênero". (BUTLER, 2017, p. 42) O ser humano "nasce" entre $8^{\mathrm{a}}$ e $13^{\mathrm{a}}$ de gestação - quando já é possível a realização dos exames de identificação do sexo do bebê, antes disso no máximo é uma mera vida e não uma vida qualificada, quando muito é enxergada como pura potencialidade digna de ser vivida. Em Tortura e a ética da fotografia: pensando com Sontag (2009) lemos:

[...] pensemos o humano como um valor e uma morfologia que podem ser atribuídos e retirados, enaltecidos, personificados, degradados e negados, elevados e afirmados. A norma continua produzindo o paradoxo quase impossível de um humano que não é humano, ou do homem que apaga o humano como um alteridade conhecida. Se existe um humano, existe um inumano; quando proclamamos como humano um determinado grupo de seres que anteriormente não eram considerados de fato humanos, admitimos que a reivindicação da condição humana' é uma prerrogativa mutável. (BUTLER, 2015, p.117)

A questão seria quais são não apenas as condições de possibilidade da identidade mas quais são as possibilidades de uma noção geral do que é humano ser coerente e auto idêntica tendo em vista as divisões de gênero e os demais meios de leitura dos corpos e das expressões de existência. Aqui vemos que a identidade e talvez a humanidade são apenas possíveis enquanto normatividade, isso é, táticas socialmente geradas, mantidas, reproduzidas para estabilizar e produzir corpos coerentes calcados em uma disposição precisa e esperada de sexo-gênero-sexualidade. Ora, com a presença dos seres abjetos, 
incoerentes, descontínuos (...) queers, que apenas parecem portarem pessoalidade, mas, por terem uma leitura incompatível com o esperado, não podem adentrar a máquina-humana.

Tais criaturas serão perjúrios na medida em que mantiverem uma relação para com as normas que lhe são opostas - o mesmo dispositivo que estabelece paridade entre sexo biológico, o gênero e a sexualidade é que proporciona existência resistentes.

\section{Da compulsoriedade hegemônica: pertencialidade ao longo do tempo}

Reiterando Michel Haar ao falar de Nietzsche, Butler aponta para o erro comum de confundir a estrutura gramatical (sujeito + predicado) com uma realidade ontológica de substância e atributo - as identidades, por conta da sua simplicidade e ordem são artifícios que jamais podem representar a realidade - a crítica da substância se volta a pessoa psicológica: o eu, o indivíduo, a pessoa, são frutos de conveniência. As crenças das categorias gramaticais são apostas nas possibilidades de traduzir a vontade se ser causa, o "eu” só possuí, stricto sensu, enquanto realidade linguística. ${ }^{6}$

O gênero, na interpretação butleriana da obra de Wittig - embora criticada ${ }^{7}$ retomada em parte -, é uma a marca não arredada quando falamos de linguagem e consequentemente, ontologia e reconhecimento. Sendo de fato uma qualificação antes de ser uma designação, a binarização dos gêneros é universalizada responde aos anseios do que ela chama de "heterossexualidade compulsória", uma sistema fundado na economia erótica falocêntrica que se politiza de uma determinada noção de natureza aos propósitos da sexualidade reprodutora - divisão masculino e feminino ou necessidade econômica heterossexual -, para que a heterossexualidade seja naturalizada há todo um movimento de discriminação linguística do sexo; este é desde sempre feminino, só há um "sexo": o feminino, particular e relativo; o masculino não é sexuado, o macho no interior desse sistema é "universal". De maneira resumida: a distinção entre o UNIVERSAL e o PARTICULAR condiciona uma relação de sujeição. O sexo masculino que por sua vez implica/envolve/abarca o outro é uma interpretação política e cultural do corpo pela mentalidade heterossexual, o sexo discursivamente produzido e difundido por um significações particulariza pela identificação com o "sexo" as figuras lidas e expressas como

6 E aqui é importante notar que o fato de está assentado na linguagem não nega os efeitos que dela provém.

7 Embora o foco não seja a crítica, vale apontá-lá rapidamente: Wittig estaria reproduzindo o humanismo e os modelos hegemônicos de representação mesmo quando considera a lésbica para além da categoria de sexo - o sujeito universal sem marcadores sexuais seria "a promessa normativas dos ideais humanistas cuja premissa é a metafísica da substância”. (BUTLER, 2017, p. 48)

Periódicus, Salvador, n.11, v. 1, mai-out.2019 - Revista de estudos indisciplinares em gêneros e sexualidades Publicação periódica vinculada ao Núcleo de Pesquisa NuCuS, da Universidade Federal da Bahia - UFBA ISSN: 2358-0844 - Endereço: http://www.portalseer.ufba.br/index.php/revistaperiodicus 
mulheres, gays, pessoas trans, etc.

O sexo é efeito na realidade de um processo violento, dissimulado, percebido como totalidade do que existe por características físicas colocado em uma ordem natural. O sexo impõe uma unidade artificial a um conjunto de atribuições que, de outro modo, seriam descontínuos. Como discursivo e perceptivo o "sexo" denota uma linguagem que forma uma percepção, modela à força das inter-relações pelas quais os corpos físicos são percebidos. As estruturas históricas heteressexuais e compulsórias distribuem aos homens autoridade e plenitude de "verdade", negando-os a todos aqueles que estão na "particularidade". A linguagem repetida ao longo do tempo produz efeitos na realidade que são percebidos com "fatos dados de uma realidade", mas que na prática não são.

A nomeação do "sexo" é um ato performativo institucionalizado que cria, regula e organiza a realidade social pela construção discursiva dos corpos segundo princípios da diferença sexual e somos obrigados a corresponder à ideia de natureza que foi estabelecida para nós - isso é político e não natural. Gênero, sexualidade e identidade não são dissociáveis:

A coerência ou a unidade internas de qualquer dos gêneros, homens ou mulher, exigem assim uma heterossexualidade estável e oposicional. Essa heterossexualidade institucional estável e oposicional. Essa concepção de gênero não só pressupõe uma relação causal entre sexo, gênero e desejo, mas sugere igualmente que o desejo reflete ou exprime o gênero, e que o gênero reflete ou exprime o desejo. (BUTLER, 2017, p. 52)

Percebemos que a substância eterna não passa de ficção: ${ }^{8}$ a compulsão por uma ordem é questionada pela a tangibilidade das suas sequências de coerência. Homem e mulheres como ideias bem definidas precisam ser revistos por conter atributos criados para sua própria regulação. $\mathrm{O}$ gênero e pessoalidade são performativos:

Se os atributos e atos do gênero, as várias maneiras como o corpo mostra ou produz sua significação cultural, são Performativos, então não há identidade preexistente pela qual um ato ou atributo possa ser medido; não haveria atos de gênero verdadeiros ou falsos, reais ou distorcidos, e a postulação de uma identidade de gênero verdadeira se revelaria uma ficção reguladora. $\mathrm{O}$ fato de a realidade do gênero ser criada mediante performances sociais contínuas significa que as próprias noções de sexo essencial e de masculinidade ou feminilidade

8 E teremos uma ferramenta de revisão das teorias clássicas muito interessante, Santo Tomás de Aquino, que falamos anteriormente, seria lido a partir de uma perspectiva não universalista, essencialista, sem perspectivas de uma finalidade, sem o aparato metafísico da divindade e sem a ligação dos sujeitos políticos por natureza.

Periódicus, Salvador, n.11, v. 1, mai-out.2019 - Revista de estudos indisciplinares em gêneros e sexualidades Publicação periódica vinculada ao Núcleo de Pesquisa NuCuS, da Universidade Federal da Bahia - UFBA ISSN: 2358-0844 - Endereço: http://www.portalseer.ufba.br/index.php/revistaperiodicus 
verdadeiras ou permanentes também são constituídas, como parte da estratégia que oculta o caráter performativo do gênero e as possibilidades performativas de proliferação das configurações de gênero fora das estruturas restritivas da dominação masculinista e da heterosscxualidade compulsória. Os gêneros não podem ser verdadeiros nem falsos, reais nem aparentes, originais nem derivados. Como portadores críveis desses atributos, contudo, eles também podem se tornar completa e radicalmente incríveis. (BUTLER, 2017, p. 244)

Um esforço de romper certas ditames da representação pode ser encontrado no que a própria autora chama de paradoxo da referencialidade. Aqui novamente a temporalidade é determinante para falarmos da constituição do sujeito, contudo somada a uma ordem nova: o poder. O sujeito é resultado do devir-ser-sujeito e da subordinação pelo poder.

\section{Do sujeito e do assujeitamento: a volta de si mesmo}

A sujeição possui dois umbrais, o poder externo, que age por subordinação - a condição de existência do sujeito e trajetória do seu desejo - e o processo de se tornar sujeito, "consiste precisamente nessa dependência fundamental de um discurso que nunca escolhemos, mas que paradoxalmente, inicia nossa ação”. (BUTLER, 2017, p. 10) Na sua primazia, o sujeito existe apenas quando submisso primário ao poder.

Contudo, Butler não se limita a repetir as ideias de Foucault sobre a circularidade e disposição do poder indo além quando pergunta-se qual a forma que o poder toma na psique: o poder que soa como externo, que o sujeito sofre diante a centralidade que emana, será a baliza para a própria identidade pessoal - a consciência infeliz do escravo hegeliano compor-se-á no teatro inconsciente partindo do enredo do senhor arbitrário que volta como fundamento da realidade psíquica.

Essa é a imagem do retorno - "uma volta a si mesma ou até contra si mesma", (BUTLER, 2017, p. 11) "inauguração topológica do sujeito, um momento fundador cujo status ontológico se mantém permanentemente incerto". (BUTLER, 2017, p. 11) É um dilema tropológico: porque não podemos pensar um sujeito que internaliza sem que ele esteja formado, nem sequer podemos verificar. Dessa forma, nos referimos àquilo que não existe. Restando-nos essa volta produtora como operação linguística que reflete e encena aquilo que tenta referenciar. ${ }^{9}$

9 E é aqui não esqueçamos que podemos relacionar esse "vazio" fundacional para as teorias da representação acima comentadas, essa espera que nunca chega do ideal adiante, para usar uma expressão derridadiana. 
Inferimos que a representação e ensaio de representar é a priori, em assunto de argumento, aquilo que não existe, ${ }^{10}$ mas se faz inteligível por usos linguísticos, derivados jurídicos e processos psíquicos subjacentes a obviedade da consciência. Contra a ideia de que o sujeito é apegado à sua subordinação por culpa, a filósofa, considera o apego a sujeição pelo poder: "o sujeito é formado por uma vontade que se volta sobre si e assume uma forma reflexiva, então o sujeito é a modalidade de poder que se volta sobre si; o sujeito do poder em recuo". (BUTLER, 2017, p. 15)

Nenhuma subordinação surge sem apego aquele que é dependente - paixão primária na dependência, mesmo quando ela é negativa. A autonomia é relativa à subordinação e se essa é reprimida, o sujeito surge em conjunção com o inconsciente. Mas, sujeito e indivíduo não são as mesmas categorias críticas e quando falamos de representação.

O primeiro é uma categoria linguística, estrutura em formação, um lugar no qual o indivíduo ocupa e desfruta de uma leitura coesa, o segundo precisa primeiro passar por uma série de processo de subjetivação. $\mathrm{O}$ ato de narrar a constituição do sujeito, pressupõe de maneira paradoxal que: 1) que a constituição do sujeito já aconteceu e 2) e que é possível relatar a narrativa deixou clara - por isso o sujeito precisa sair da própria perspectiva para contar sua gênese, logo, se opor a subordinação é reiterar sua sujeição - o poder exercido sobre é também o poder assumido pelo sujeito.

Pressupor é igual a restabelecer e ambos o sujeito (re)produz e quando faz isso são performadas as condições de vulnerabilidade temporal das condições de subordinação, o poder passa de condição para a ação propriamente dita do sujeito: de fato, existe uma descontinuidade das possibilidades que o poder assume e as condições de possibilidade de existência do poder: "ao agir, o sujeito retém as condições de seu surgimento, isso não significa que toda sua ação continue presa a essas condições nem que elas sejam as mesmas em todas as ações”, (BUTLER, 2017, p. 21) assumir o poder não é deslocálo, intactamente de um lugar ao outro e sim uma alteração da forma como é apropriado ou assumido para com o poder que lhe deu possibilidade e que se volta contra.

A resistência ao poder é um misto de resistência que é na verdade recuperação do poder “original” e uma recuperação que é uma resistência dissidente.

${ }^{10}$ Em argumento pois na atualidade do mundo sucederia todas as simultaneidades sem ordenamento tão bem circunscrita. 


\section{Representação e dissidência}

Há uma luta incessante - manipulação e mantimento - de poder entre os sujeitos comportados e os desviantes no qual a representação do (S)ser ou ser representado jamais é estática fora da contingência do tempo partindo de uma abstração que seria o ponto derivativo, ou seja existe, nas práticas concretas no qual o poder e os sujeitos estão em trocas e contatos constantes dificilmente poderíamos escapar às inúmeras situações em que os mecanismos de sujeição e assujeitamento se modificam tanto no plano jurídico quanto no cotidiano nas relações interpessoais e interpessoal. As identidades e os sujeitos são constituídos por performances que devem ser compulsoriamente repetidas e é devido a essa repetição que há a sua legitimação e a abertura para seu contrário, afinal, são nesses espaços que seriam possíveis demonstrar a sua teatralidade e a fomentação das atitudes paródicas dos gestos, dos conceitos e das formas de vida desviante - não poderíamos, por exemplo, falar linguisticamente de um cis se não tivermos um trans e vice-versa.

Para Butler, a representação ao invés de ser inclusiva ela também não seria a grosso modo a exclusão pois a essa toma deliberadamente o ponto de vista no qual o que está fora jamais assombra, e sim uma volta ao paradoxo da própria fundação que é vazia, organizada de forma específica a proporcionar inteligibilidade aos discursos que se dizem pré-discursivos e fora do corpo epistemológico, normativo e linguístico que se diz operar.

Talvez, partindo de um ponto de vista na qual a humanidade - sem levar as ruínas a noção de humano que toda a antropologia filosófica de Butler acarreta - não estaria a caminho de uma emancipação teológica-histórica, ${ }^{11}$ a vida social e a identidade são produtos e produtoras de efetivação

11 Aqui seria interessante um trabalho mais explícito sobre a relação do ser humano e da história, mas devido a forma de escrita do texto retomo a consideração de Agamben no texto Tempo e história - crítica ao instante e do contínuo: a mente humana leva em si a experiência do tempo, porém, não sua representação. Esse ocorre por intermediação de imagens espaciais. Os condicionamentos da experiência do tempo estão implícitos em qualquer concepção de história. A tarefa de uma revolução por excelência não é transformar o mundo mas sim de mudar o tempo. Entretanto, o pensamento político moderno não elaborou uma concepção do tempo análoga aos seus esforços de reformulações no âmbito da história - isso pode ser visto no próprio materialismo histórico e por isso foi forçada a recorrer a tradição ocidental, resultado: simultaneamente prega uma revolução e permite uma experiência tradicional do tempo. No cristianismo a representação do tempo é uma linha reta. o tempo é suporte para a criação e deve acabar ele. Entre a criação e o Apocalipse o período é um só. O mundo não é único, finito e limitado por dois lado, os eventos não se repetirão jamais. E mais: esse tempo tem uma direção e um sentido com um ponto de referência central na reencarnação de Cristo. Nas Confissões de Agostinho Livro XI o tempo aristotélico não é findado, simplesmente sofre uma virada do externo para o interno. Essa experiência dura pouco tempo, sendo recoberta inteiramente pelo tempo matematizado anterior, consequentemente emerge o círculo metafísico. A eternidade é encarada como anuladora a experiência humana do tempo. O instante como seu caráter inextenso e inapreensível torna-se o ponto do tempo na roda da eternidade. Nos tempos modernos o tempo cristão é mantido reto, irreversível, com exceção da ideia de finalidade e sentido que não seja o "antes" e o "depois". Essa representação nasce da experiência do trabalho realizados cada vez mais massificados.

Periódicus, Salvador, n.11, v. 1, mai-out.2019 - Revista de estudos indisciplinares em gêneros e sexualidades Publicação periódica vinculada ao Núcleo de Pesquisa NuCuS, da Universidade Federal da Bahia - UFBA ISSN: 2358-0844 - Endereço: http://www.portalseer.ufba.br/index.php/revistaperiodicus 
e desefetivação das representações, ou seja, não haveriam continuidade e sim disjunções agentes e produtos dos seus objetos e escopos que se engessam nos próprios ditames.

Teríamos que pensar de maneira crítica as políticas de representatividade: nas práticas e posturas políticas e na comercialização midiática dos seus desejos o que está em jogo? O termos "representatividade" é hoje amplamente debatido nos projetos de visibilidade e acessibilidade às minorias sociais - seja na luta pelas políticas públicas e reconhecimento de voz ativa dentro dos sistemas jurídicos e executivos, seja na abertura ao mercado de trabalho ou exploração das potencialidades monetários de seus "nichos culturais" por isso se faz necessário refletir a diferença entre o ideal da representatividade e sua consumação bem como o contexto em que ambas incidem e surgem. Devemos pensar o engessamento dessas identidades em um sistema econômico que sempre se atualiza abarcando e reconfigurando seus sujeitos e capitais podendo apontar para (I) o reconhecimento de certas vidas dignas de serem vividas, (II) a inteligibilidade de certos discursos sobre essas pessoas que performam suas identidades e sexualidades, (III) a reprodução de saberes sobre as sexualidades que servem de joguetes de poderes e interesses e (IV) a abertura para um mercado gigantesco calcado na estabilidade encerrada, por exemplo, nas letras “LGBT”. Mas esses temas só em um futuro serão analisados...

\section{Referências}

AGAMBEN, G. Infância e História. Belo Horizonte: EdUFMG, 2005. p.109 -128.

AQUINO, S. T. Escritos políticos de Santo Tomás de Aquino. Rio de Janeiro: Vozes, 1993.

BOBBIO, N.; MATTEUCCI, N.; PASQUINO, G. et al. Dicionário de política. 5. ed. Brasília: Ed.UnB, 1998.

BUTLER, J. A vida psíquica do poder: teorias da sujeição. Belo Horizonte: Autêntica Editora, 2017. (Coleção Filô).

BUTLER, J. Problemas de gênero: feminismo e subversão da identidade.15. ed. Rio de Janeiro: Civilização Brasileira, 2017. (Sujeito e História).

BUTLER, J. Tortura e a ética da fotografia: pensando com Sontag. In: Quadros de Guerra: quando a vida é passível de luto? .15. ed. Rio de Janeiro: Civilização Brasileira, 2015. p. 99- 149.

Nas cidades e nas fábricas surgem o tempo morto e subtraído da experiência. O instante agora é em si o sentido verdadeiramente histórico. O pensamento contemporâneo deveria buscar de uma nova forma de conceber o tempo partindo de uma crítica dessa tempo contínuo.

Periódicus, Salvador, n.11, v. 1, mai-out.2019 - Revista de estudos indisciplinares em gêneros e sexualidades Publicação periódica vinculada ao Núcleo de Pesquisa NuCuS, da Universidade Federal da Bahia - UFBA ISSN: 2358-0844 - Endereço: http://www.portalseer.ufba.br/index.php/revistaperiodicus 
FRASER. N. Da redistribuição ao reconhecimento? Dilemas da justiça na era pós- socialista. In: SOUZA, J. (org.). Democracia Hoje: novos desafios para a teoria democrática contemporânea. Brasília, DF: Ed.UnB, 2011. p 245-282.

LACERDA, B. A. Jusnaturalismo e direitos humanos. Revista interdisciplinar de direito, Rio de Janeiro, v. 8, p. 105-112, 2011. Disponível em: http://www.faa.edu.br/revistas/fdv-2011. Acesso em: 25 jun. 2017.

MOURA, D. O. A doutrina do direito natural em Tomás de Aquino. Jurisprudência Mineira, Belo Horizonte, v. 55, n. 168, p. 21-41, 2004. Disponível em: https://bd.tjmg.jus.br/jspui/bitstream/tjmg/644/1/D2v1682004.pdf. Acesso em: 17 jun. 2018 .

PHILLIPS, A. De uma política de ideias a uma política de representação. Revista de Estudos Feministas, Florianópolis, v. 9, n. 1, p.268-289, 2001. Disponível em: https://periodicos.ufsc.br/index.php/ref/article/view/S0104-026X2001000100016/8915. Acesso em: 18 jun. 2018.

YOUNG, I. M. Representação política, identidades e minorias. Lua Nova, São Paulo, n. 67, p.139-190, 2006. Disponível em: http://www.scielo.br/pdf/ln/n67/a06n67. Acesso em: 18 jun. 2018. 